\title{
Erratum to: The interaction of carbon dioxide and hypoxia in the control of cerebral blood flow
}

\author{
Alexandra Mardimae - Dahlia Y. Balaban - Matthew A. Machina • \\ Anne Battisti-Charbonney • Jay S. Han • Rita Katznelson • \\ Leonid L. Minkovich • Ludwik Fedorko • Patricia M. Murphy • \\ Marcin Wasowicz • Finola Naughton • Massimiliano Meineri • \\ Joseph A. Fisher • James Duffin
}

Published online: 8 December 2012

(C) Springer-Verlag Berlin Heidelberg 2012

\section{Erratum to: Pflugers Arch - Eur J Physiol}

\section{DOI 10.1007/s00424-012-1148-1}

The original version of this article inadvertently contained a mistake.

Due to the large number of authors participating in these experiments, Dr. Anne Battisti-Charbonney was inadvertently omitted from the list of authors but should have been included.

Her affiliation at the time of these experiments was: Department of Physiology, University of Toronto, Ontario, Canada.

The online version of the original article can be found at http://dx.doi.org/ 10.1007/s00424-012-1148-1

\footnotetext{
Toronto, ON, Canada M5S 1A8

J. Duffin $(\bowtie)$

Thornhill Research, Inc,

210 Dundas St., W. Suite 200,

Toronto, ON, Canada M5G 2E8

e-mail: j.duffin@utoronto.ca
}

A. Mardimae $\cdot$ D. Y. Balaban $\cdot$ M. A. Machina

A. Battisti-Charbonney $\cdot$ J. S. Han $\cdot$ J. A. Fisher $\cdot$ J. Duffin

Department of Physiology, University of Toronto,

R. Katznelson • L. L. Minkovich • L. Fedorko • P. M. Murphy •

M. Wasowicz $\cdot$ F. Naughton $\cdot$ M. Meineri $\cdot$ J. A. Fisher $\cdot$ J. Duffin

Department of Anaesthesia, University of Toronto

and University Health Network, Toronto, ON, Canada 